\title{
Imagens da multidão: carnaval e mídia ${ }^{1}$
}

\section{Beatriz Jaguaribe}

\section{Resumo}

Por meio da leitura seletiva de representações artísticas e midiáticas, este ensaio explora como um tipo específico de multidão - a multidão carnavalesca - foi interpretada em distintos períodos da história do Rio de Janeiro. Mais do que qualquer outra celebração pública, o carnaval foi e ainda é o ritual festivo que melhor espelha as negociações culturais da cidade. Argumento que as diferentes mídias não somente expressam as contradições sociais e as diversas negociações culturais desta celebração profana como também moldam as próprias manifestações da multidão.

\section{Palavras-Chave}

Carnaval. Multidão. Mídia. Cidade.
Beatriz Jaguaribe | beajaguar@gmail.com Professora do Programa de Pós-Graduação da Escola de Comunicação da Universidade Federal do Rio de Janeiro (ECO-UFRJ)

\section{0 retorno da multidão}

Sob o sol escaldante do verão carioca, a festa de Momo é um assalto aos sentidos. Cheiros de lixo, suor, urina e álcool impregnam a cidade. Sons de percussão, gritaria, música estridente e cantorias variadas trituram o silêncio. Como festa apoteótica da carne, o carnaval é também a consagração da exibição corporal. Corpos siliconados, mascarados, enfeitados, gloriosos e grotescos dançam, cantam, bebem, beijam e urinam nas ruas, praças, salões, palcos e no Sambódromo. Como festividade popular e midiática, o carnaval é o delírio das imagens e 0 momento de destaque de anônimos e celebridades. Todo ano dá-se a encenação da repetição e inovação de imaginários díspares expressos na coreografia, nas roupas, nas músicas e nos detalhes técnicos. Mas, entre todos estes e outros fatores que sobejamente identificam o carnaval, há um ingrediente que tem se destacado e gerado grande impacto na cidade e considerável repercussão na mídia. Trata-se do retorno da multidão festiva ocupando as ruas da cidade. Nos últimos anos, o Rio de Janeiro 
tornou-se a cidade com a maior concentração de foliões de carnaval de rua de todo o Brasil. $^{2}$

A reemergência do carnaval de rua no Rio de Janeiro esteve diretamente acoplada ao ímpeto dos blocos carnavalescos. ${ }^{3}$ De acordo com a pesquisa de Teresa Guilhon, os 12 blocos fundadores que compõem a associação SEBASTIANA eram motivados por agendas de reconquista do espaço público e tinham 0 propósito específico de voltar a ocupar a rua por meio da recuperação das tradições carnavalescas. Entretanto, as arguições políticas e culturais dos fundadores de alguns blocos não englobam, necessariamente, os desígnios de milhares de pessoas que escolhem participar do carnaval de rua. Sobretudo a redemocratização do país, a valorização da cultura popular e midiática e 0 saldo lucrativo da festa de Momo potencializaram de forma explosiva não somente os desfiles do Sambódromo, mas o próprio carnaval de rua. Durante a ditadura militar, nos anos 1960-70, 0 carnaval de rua esmaeceu. Mas o carnaval de rua no Rio de Janeiro esvaziou-se não apenas por conta da atmosfera repressiva da ditadura militar; este perdeu força face à implementação massiva dos meios de comunicação televisivos que, liderados pela Rede Globo, ofereciam cobertura total dos desfiles das Escolas de Samba. A construção do Sambódromo, em 1984, removeu os desfiles do centro da cidade, colocando-os numa arena específica restrita aos pagantes do caríssimo ingresso. No entanto, argumento que o próprio excesso de cobertura midiática do carnaval carioca gerou também 0 enfado com 0 carnaval-espetáculo. 0 carnaval de rua assinala 0 desejo do retorno da multidão.

Neste ensaio, exploro como um tipo específico de multidão - a multidão carnavalesca - tem sido avaliada em diversos momentos da história carioca. Embora indivíduos possam ter motivos variados para se imiscuírem na multidão, a presença da multidão carnavalesca na metrópole contemporânea assinala a celebração de um pertencimento coletivo e expressa a jocosidade performática dos foliões urbanos. A multidão carnavalesca nas ruas enfatiza a presença corporal e se opõe, neste sentido, à dimensão espectral das audiências dos meios de comunicação de massas. Com isso, não viso endossar a disjunção entre a presença da multidão no espaço público e os meios de comunicação. De forma semelhante aos diversos tipos de aglomerações humanas no espaço público, as multidões que se aglutinam nos blocos

Uma versão em inglês deste ensaio intitulado, "Carnival Crowds", foi publicado no livro, Sociological Review Monograph Series, editado por Robin James Smith e Kevin Hetherington, Wiley Blackwell, Inglaterra, 2013

Segundo os dados do site www.rankbrasil.com.br, o Rio de Janeiro é a cidade que tem o maior carnaval de rua do país. Em 2013, o carnaval atraiu 5,3 milhões de foliões, reuniu 492 blocos e gerou receita de 848 milhões de dólares para a cidade. Ver a notícia "Carnaval de rua do Rio de Janeiro deve quebrar recorde de público", por Fátima Pires, 17/01/2013. 
carnavalescos também fazem uso dos meios de comunicação como fonte de troca e de informação. De fato, muitas aglomerações começam como pontos isolados na rede digital para depois ganharem concretude nas ruas. Mas o chamado das ruas potencializa o contato corporal. Este chamado corporal carnavalesco evoca energias que podem ser domesticadas ou liberadas como manifestações de êxtase; enquanto a aparição do maravilhoso, como a ruptura do cotidiano e como expressão da paixão transformadora do corpo festivo. Em sua versão negativa, a experiência de estar no miolo da multidão pode provocar pânico, náusea, impaciência ou medo. Seja na sua versão celebratória ou na sua versão distópica, o sentimento de estar envolto pela multidão é impactante precisamente porque a multidão esgarça as fronteiras entre 0 eu e 0 outro.

A presença do habitante urbano contemporâneo no bojo da multidão festiva torna-se um contraponto à esfera fragmentada do consumo, à individualidade do mercado competitivo $\mathrm{e}$ ao isolamento da audiência midiática. Estou sugerindo que a experiência de estar na multidão carnavalesca oferece um contraste às teorias da escola de Frankfurt sobre a alienação massiva encampada pela indústria cultural. Mas 0 mergulhar na multidão carnavalesca é também uma experiência diversa da noção de multidão tal como foi formulada por Hardt e Negri (2004). A experiência da multidão carnavalesca difere da multidão de Hardt e Negri porque agendas políticas não são necessariamente encampadas na folia momesca. Sobretudo, a singularidade de cada participante na multidão é reforçada pela dança e pelos disfarces, mas também é apagada quando as pessoas convergem juntas para se aglutinarem na multidão, ocupando as ruas da cidade. A despeito de diferenças sociais gritantes, da discriminação racial e de gênero e da manutenção de privilégios sociais, o Rio de Janeiro se transformou - por meio do impacto de suas numerosas favelas, das lutas pela cidadania e do surgimento de novas agendas políticas - numa cidade mais democrática e também mais culturalmente populista. 0 apelo do carnaval enquanto momento de trégua, inversão da hierarquia e manifestação de descarga catártica perdura; porém, as estruturas do cotidiano contra as quais a festa transgredia se modificaram.

Embora as origens do carnaval brasileiro tivessem sido pautadas pelo calendário religioso católico -0 carnaval ocorre sete domingos antes do domingo de Páscoa -, o carnaval das escolas de samba, dos bailes em salões fechados e da folia nas ruas da cidade não evoca crenças religiosas ou transcendentais. Ao contrário, o carnaval atiça 0 deleite carnal e 0 êxtase no reino deste mundo. Ao endossar ativamente um engajamento antipuritano e sensorial com o mundo, 0 ímpeto carnavalesco é o oposto da postura acética e da contemplação meditativa. 0 carnaval é a festa da emersão na carne do mundo. Embora muito motivos comerciais possam ser atribuídos à manutenção da prática carnavalesca, as multidões que participam da festa não estão motivadas 
pelo lucro monetário. Diversamente da multidão apinhada para escutar concertos de música ou das que torcem durante eventos esportivos, a multidão carnavalesca é engajada consigo mesma. A música ao vivo é um fator essencial da animação, mas a dança, os disfarces, a bebida e o próprio ato de fazer parte da multidão em si constituem também o cerne da experiência do carnaval de rua. Enquanto o carnaval de rua desapareceu das principais cidades europeias e somente existe de forma limitada e coreografada em Veneza, Nice e Nova Orleans, nos Estados Unidos, no Brasil, o carnaval tem o Rio de Janeiro, sua segunda maior cidade, como o palco central da festividade (MORAES, 1958)0 retorno bombástico do carnaval de rua e a presença avassaladora da multidão trazem à tona perguntas cruciais sobre a viabilidade da festa, sobre os limites do convívio, sobre o ímpeto da multidão e sobre 0 papel dos diferentes agentes artísticos, políticos e midiáticos nesta orquestração. A presença da multidão festiva numa metrópole também assinala modalidades culturais específicas que ensejam formas de modernidades alternativas.

\section{Multidões e massas na metrópole}

No aperto do metrô, na congestão das calçadas, nas lojas repletas de ávidos consumidores, a cidade é o local de confluência da multidão. Evidentemente, o desenho urbanístico modifica a possibilidade do contato humano e influi sobre a formação da multidão. Cidades descentradas e comandadas pela circulação do automóvel, como Los Angeles, possuem menos espaços públicos propícios à aglutinação da multidão. Inversamente, cidades com centros simbólicos, transporte público, densidade urbana e uma malha de ruas para pedestres possibilitam a confluência das multidões. As multidões se aglomeram em arenas metropolitanas por uma variedade de objetivos que englobam motivos políticos, campanhas morais, festividades religiosas, passeatas por direitos civis ou identitários ou simplesmente se reúnem em eventos aleatórios que semeiam a aglomeração de pessoas. Como Sennett (1977) e tantos outros pesquisadores argumentaram, um aspecto crucial do declínio do espaço público esteve também relacionado às mudanças nas práticas sociais com as quais as pessoas ocupavam as ruas da cidade. Nas grandes metrópoles ocidentais do século XIX, novos códigos de silêncio e recato público foram adotados para garantir a privacidade dos estranhos no âmbito público. Em seu renomado livro Massa e Poder - Canetti ( 1973, p.15, tradução nossa) detalha que a repugnância de ser tocado por estranhos é parte da vivência metropolitana, mas também assevera que: "É somente na multidão que um homem perde 0 medo de ser tocado (...) Canetti (1973, p.18, tradução nossa) enfatiza:

Somente estando juntos é que os homens podem se liberar do peso da distância; e isso, precisamente, é 0 que ocorre na multidão. Durante a descarga as distinções são eliminadas e todos se sentem iguais... É por causa deste momento abençoado, em que ninguém 
é melhor ou pior do que o outro, que as pessoas se transformam em uma multidão.

Embora o livro de Canetti ofereça uma ampla tipologia cultural e uma abrangente análise sobre a formação da multidão, sua obra foi escrita sob 0 impacto da formação das multidões fascistas que, nos anos 1940, eram comandadas por líderes carismáticos. Trago à tona seus argumentos porque o retorno da multidão, no contexto da modernidade tardia de sociedades altamente midiáticas e democráticas sugere outro tipo de agenciamento coletivo. Este retorno da multidão nos fala da necessidade específica da troca social e corporal que surge como uma resposta ao âmbito espectral dos domínios midiatizados. A presença da multidão nas ruas e praças também designa formas de ocupar espaços urbanos que têm sido crescentemente privatizados ou transformados em arenas de consumo. Cada multidão terá seus repertórios de sentimentos, nuances de afeto e motivações políticas, culturais e históricas. Torna-se uma tarefa impossível catalogar qual é 0 "sentimento" generalizado da multidão sem incorrer em tipologias redutoras. De fato, o que Canetti assinala como sendo impulsos cruciais da multidão - a derrocada das hierarquias e 0 desejo de pertencimento coletivo - tem sido assunto de debate e teorização (SCHNAPPS;TIEWS, 2006). Entretanto, a pergunta persiste sobre a necessidade de estar fisicamente presente no espaço público quando os meios de comunicação permitem a existência de multidões espectrais que não possuem contato corporal algum entre si.
No século XIX, há um uso ambivalente dos termos massas e multidão. Com a difusão da escolaridade e mediante 0 fortalecimento de sistemas de representação democrática, as massas são entrevistas como a multidão irracional, mas também são retratadas como 0 povo soberano e como as classes trabalhadoras (JONSSON, 2006). No século XX, a popularização de novas formas de comunicação, tais como o cinema e 0 rádio, deram ao termo "massas" um novo significado - as massas também se transformaram em sinônimo das audiências midiáticas. As massas mobilizadas durante as décadas de 1930 e 40 eram compreendidas como povo, como a classe trabalhadora e também como os espectadores/consumidores dos meios de comunicação massiva. Enquanto a palavra "crowd"em inglês significa uma multidão de pessoas aglutinadas fisicamente num espaço material, a noção de massa pode abarcar amorfas audiências que consomem mensagens, imagens, narrativas e informação pelos meios midiáticos, como jornal, cinema, rádio, televisão e meios digitais (MARTIN-BARBERO, 1997)

Nos estudos de mídia, a noção de massa tem sido acirradamente discutida já que este termo ganhou conotações díspares que vão da crítica cáustica de Adorno sobre a passividade das audiências massivas da indústria cultural ao hino celebratório da aldeia global de participação massiva exaltado por McLuhan. Na conhecida versão marxista, as massas são entrevistas ora como o proletariado oprimido 
domesticado pelas classes dominantes, ora como a força motriz da história que desmontaria o status quo em prol da utopia do futuro (BUCK-MORSS, 2000). Em La rebelión de las masas (1930), cuja primeira edição foi publicada em 1930, Ortega y Gasset (1883-1955) define as massas como a própria encarnação da mediocridade democrática. Para Ortega, o "homem-massa" existe independentemente de afiliações de classe, porque ele simboliza aquilo que Nietzsche deplorava como sendo a constituição da mentalidade conformista, aprisionada e copiadora da manada desprovida de criatividade. A crítica contemporânea ao uso do termo "massa" foi motivada como uma reação contra as generalizações abrangentes do termo, já que indivíduos moldados por afiliações de classe, formas de pertencimento, modos de afetividade subjetiva e práticas identitárias díspares são uniformemente categorizados por uma rubrica que oblitera as variações entre as pessoas (CAREY, 1992).

As transformações na ocupação do espaço público contemporâneo levaram muitos a questionarem a importância da multidão enquanto protagonista da transformação social. Neste veio, Schnapps ( 2006, p.xi, tradução nossa) argumenta que a "era das multidões" já teria terminado porque nas sociedades pós-industriais teríamos "[...] proliferação e o predomínio crescente de modos virtuais ou midiáticos de 'assembleia' ao invés das assembleias fisicamente constituídas"
Schnapps (2006, p.xi, tradução nossa) detecta uma tendência que é:

[...] menos de ruptura e mais um processo de especialização cujo resultado final é a progressiva redução do papel físico das multidões ao estatuto de um ícone que circula numa economia política caracterizada pela coexistência da agregação midiática e da desagregação corporal.

Afora os fatores comunicacionais e socioeconômicos alinhados por Schnapps, outro elemento de relevância simbólica contribuiu para o esmaecimento da multidão nas sociedades ocidentais. Este elemento simbólico se refere ao esgarçamento dos imaginários do futuro. 0 impacto da multidão e as teorias sobre as massas alcançaram um apogeu nos anos 1930-40, quando as disputas ideológicas entre o fascismo, o comunismo e 0 capitalismo liberal eram travadas em torno da captura das mentes e corações das massas, retratadas em cartazes, exortadas em assembleias e estetizadas em documentários e fotografias públicas. 0 esvaziamento dos imaginários utopistas seculares do futuro e 0 apagamento dos mundos sonhados da utopia para as massas enfraqueceram a presença ativa da multidão nas sociedades ocidentais (BUCK-MORSS, 2000)

\section{Multidões cariocas}

Ao longo do século XIX e durante grande parte do século XX, a retratação da multidão no Rio de Janeiro foi mediada pelas tendências do pensamento social europeu e pela imaginação artística encampada pela cidade letrada. Mas 
uma diferença crucial caracterizou a composição das massas metropolitanas cariocas. 0 Rio de Janeiro foi um dos maiores portos de escravos de todas as Américas (KARASCH, 1987). Durante o Império (1822-1889) e até a derrocada da República Velha em 1930, a sociedade carioca era altamente hierárquica. Às classes populares eram vetados direitos civis, participação democrática e poder político. Escravos alforriados, imigrantes pobres e uma debilitada pequena burguesia compunham as escalões mais baixos e medianos da sociedade. 0 advento da república em 1889 pouco contribuiu para alterar as condições dos trabalhadores pobres e para minorar as divisões hierárquicas de classe, raça e gênero. Até a década de 1930, a cidade apresentava uma esfera pública reduzida, na qual a "cidade letrada", composta de funcionários graduados, políticos, administradores, advogados, médicos, engenheiros e membros do clero, detinha as redes de poder. Tal como já foi tantas vezes mencionado na historiografia da cidade, a abolição da escravatura provocou júbilo massivo na população pobre, já o mesmo não se pode dizer sobre a proclamação da república. No seu conhecido livro 0s bestializados, José Murilo de Carvalho (1987) analisa como a imprensa retratou a reação popular à proclamação da república descrevendo-a como passiva, inexpressiva e bestializada. Carvalho enfatiza, entretanto, que a aparvalhada reação popular não foi meramente 0 resultado da passividade, mas também foi o fruto da desconfiança popular em relação às manobras políticas das classes dirigentes. Mas se as classes populares foram excluídas do poder político e econômico, o mesmo não se pode dizer de sua influência cultural.

Já no século XIX e ao longo do século XX, a multidão carnavalesca enfatizara a força das festividades coletivas. Embora a multidão de protesto, a multidão esportiva e a multidão religiosa marcaram presença em vários momentos da história da cidade, foi a multidão carnavalesca que assinalou os aspectos mais singulares das negociações culturais do Rio de Janeiro.

0 influente estudo de Roberto DaMatta do final dos anos 1970 argumenta que numa sociedade altamente hierarquizada, porém eivada de relações sociais ambíguas calcadas no patronato e na troca de favores, o carnaval seria a festividade da liberação catártica coletiva. (DAMATTA, 1997). Durante a folia carnavalesca, os signos sociais se invertem. Homens se vestem de mulheres, negros empobrecidos tornam-se aristocratas da corte barroca francesa e donas de casa se transformam em sereias sedutoras. DaMatta examinou os rituais e as festividades do carnaval brasileiro na sua dimensão moderna, e sua análise detalha não somente 0 elemento hierárquico da sociedade brasileira como também as negociações ambíguas das normas culturais. 0 carnaval corresponderia não apenas à transgressão das hierarquias sociais, mas também seria 0 ritual da liberação do anarquismo individual que fabrica formas de subversão e espaços de prazer. DaMatta não nega que 0 carnaval espelhe as regras da sociedade, 
mas em vez de insistir no desmascaramento do poder ou de denunciar a exploração de classe, ele busca ressaltar os aspectos socialmente criativos da celebração carnavalesca. Enfatiza, sobretudo, 0 aspecto dialético do espelhamento carnavalesco que dá margem a fissuras e a transformações.

Outros pesquisadores do carnaval (CUNHA, 2001; FEREIRA, 2004; QUEIROZ, 1992; SOIHET, 1998) diferem no tocante às características da multidão carnavalesca. Pereira de Queiroz discorda da interpretação de DaMatta, pois renega que 0 ritual carnavalesco ofereça uma trégua social ao postular que as celebrações carnavalescas estão permeadas por distinções de classe. Segundo a autora, uma das mitologias do ethos carnavalesco é justamente a crença popularizada de que festividades e a multidão desmontam ordenações hierárquicas (QUEIROZ, 1992). Propõe então que o carnaval seja compreendido como uma forma de diversão coletiva na qual as classes populares desempenham um papel específico e ocupam um espaço delimitado dentro da festividade QUEIROZ, 1992). Já Rachel Soihet enfatiza seu desacordo com Pereira de Queiroz ao afirmar que, mesmo nas novas avenidas reformadas por Pereira Passos no início do século XX, a multidão carnavalesca sempre foi composta por uma mistura de classes. (SOIHET, 1998). Finalmente, Pereira Cunha estipula que as celebrações do carnaval oscilavam entre a hierarquização e a mistura; entre as manifestações populares do Zé Pereira aportuguesado e as festas de máscaras inspiradas pelos carnavais de Veneza e Nice; entre o carnaval de elegantes bailes e 0 carnaval de rua prenhe da musicalidade afro-brasileira (CUNHA, 2001). Como Pereira de Queiroz, Pereira Cunha também enfatiza que 0 carnaval engendrou o mito da união social e da suspensão de diferenças de classe, raça e gênero. Mas ela mantém que 0 carnaval foi um modo inventivo de disputa e justaposição entre classes e tradições culturais:

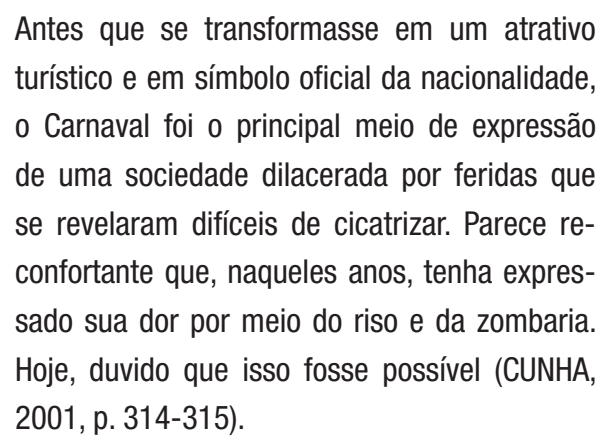

\section{Sob o signo de Momo: carnaval de máscaras e letras}

Dos seus inícios coloniais como o entrudo português que consistia numa variedade de travessuras realizadas durante os dias de carnaval - entre as quais se destacava a batalha das bolas de cheiro ou até mesmo o mero atirar de substâncias pouco aprazíveis nos rostos e corpos dos pedestres desavisados - aos preparativos altamente sofisticados para os desfiles no Sambódromo, o maior evento popular do mundo, o carnaval tornou-se praticamente sinônimo da cidade do Rio de Janeiro. No seu espelhamento das negociações entre classes, raças e gêneros, o carnaval carioca revelou as tensões, invenções e negociações culturais de sucessivos momentos 
históricos. Revelou também as ansiedades sobre a multidão embriagada e festiva nas ruas da cidade e as respostas variadas a essa "ameaça" pelas autoridades municipais e pela polícia.

No entrudo colonial, as famílias aristocráticas, resguardas no recinto dos sobrados, jogavam as bolas de cheiro e praticavam travessuras carnavalescas entre os membros da família ou com os amigos da mesma classe (CUNHA, 2001). Os escravos, evidentemente, não podiam alvejar seus amos e, mesmo entre eles, os que detinham um estatuto superior eram autorizados a praticar travessuras com os escravos hierarquicamente inferiores. Ferreira (2004) detalha que durante os dias do entrudo, os visitantes estrangeiros eram 0 alvo hilariante das bolas de cheiro atiradas pelas famílias brasileiras que estavam visitando. 0 entrudo era um evento familiar e também uma forma de diversão popular. Nas ruas estreitas do Rio de Janeiro colonial, vias de pedras toscas, iluminação precária e cheiro de pestilência, 0 entrudo era fervorosamente praticado pelos escravos e pelos habitantes pobres da cidade.

Após a independência em 1822, o entrudo, todavia, reteve sua popularidade, mas foi crescentemente desprestigiado pelas elites locais desejosas de emularem formas mais elegantes de entretenimento, tais como as bailes refinados de máscaras copiados da burguesia francesa (CUNHA, 2001; FERREIRA, 2004; GALVÃO, 2009; MORAES, 1958; QUEIROZ, 1992)
Em 1851, as primeiras associações carnavalescas são fundadas. Ao redor de 1855, não somente os bailes de máscaras nos salões tornam-se uma parte essencial da diversão carnavalesca, mas também os suntuosos carros alegóricos e as fantasias requintadas passam a adornar o cortejo das sociedades carnavalescas que desfilavam pela rua do Ouvidor (CUNHA, 2001; FERREIRA, 2004). Os desfiles das Sumidades Carnavalescas atraíam multidões e, no final do século XIX, as Grandes Sociedades, tais como os famigerados Tenentes do Diabo, Os Democráticos e Os Fenianos, organizavam imensos desfiles com carros alegóricos. Estas sociedades carnavalescas competiam entre si e também endossavam agendas políticas tais como a abolição da escravatura e a causa republicana. Desde o princípio, este carnaval das sociedades estava diretamente acoplado aos meios de comunicação, ou seja, aos jornais, que promoviam as disputas, divulgavam os puffs satíricos e organizavam os horários (COUTINHO, 2006; FERREIRA, 2004; GALVÃ0, 2009).

As classes populares compareciam na festa participando de cucumbis, conjuntos de foliões que tocavam instrumentos de origem africana nos cordões compostos por multidões de foliões pobres com fantasias caseiras e instrumentos. As classes populares também desfilavam nos ranchos, que eram as primeiras versões modestas das escolas de samba. Cunha (2001, p. 94) afirma:

0 temor da multidão carnavalesca nas ruas, da reunião excitante e excitada de gente que descia dos subúrbios e arrabaldes em bondes 
apinhados para 0 centro da cidade durante os dias de folia, foi explicitado nas décadas de 1880 e 1890 em sucessivas matérias da imprensa diária, para atingir muitos decibéis nos primeiros anos da República

As ansiedades da elite sobre 0 contágio da multidão popular afloram nos jornais no século XIX e nas primeiras décadas do século XX. Soihet cita uma reportagem do carnaval de 1912:

[...] porque em parte alguma do mundo se vê uma família que arrasta sedas e dá recepções, que passa por aristocrática e se enche de 'não me toques', esquecer todas as conveniências da elegância e do bom gosto para vir se acotovelar na praça pública com uma plebe escusa como a nossa (SOIHET, 1998, p. 56).

Olavo Bilac (1865-1918), o celebrado poeta, boêmio e jornalista, comenta, em crônica de 1901, que o carnaval atiçava todos os desejos transgressores: "É que havia lugares a que não podia ir, sem grave escândalo, o burguês prudente [...] Mas, chegado o Carnaval, o homem sério enfronhava a sua seriedade num dominó, amarrava sobre a austera face uma máscara - e adeus terrores! “(BILAC, 1997, p. 774). Entretanto, o poeta proclamou que, no início do século XX, o carnaval já tinha perdido sua verve picante, porque a lassidão moral atenuava as forças transgressoras da festa de Momo.

A máscara perdeu o seu primitivo encanto. Para cravar sofregamente os dentes na polpa do fruto proibido, já não é preciso pôr uma máscara no rosto. 0 fruto saboroso aí está, ao alcance de todas as mãos, oferecendo-se, dando-se, impondo-se, com uma impudência que já não ofende 0 duro olhar da Moral. Uma sociedade nova e atarefada, que não dispõe de tempo para ter escrúpulos, substituiu a velha sociedade patriarcal; e, assim, a máscara perdeu seu valor, porque perdeu a sua utilidade. Mas nem por isso, graças a Deus, o povo deixa de se divertir, nesses três dias de barulho. Dizem que ficar um homem amassado, molhado, pisado, imundo, resfriado, cheio de equimoses e de reumatismos, pode ser tudo, menos divertimento. Por quê? Divertimento é tudo quanto é novo, tudo quanto sai da execrável monotonia do ganha-pão e 0 do come-a-horas-certas (BILAC, 1997, p. 775).

\section{Em A alma encantadora das ruas (1908), João} do Rio (1881-1921), célebre escritor, jornalista, dândi decadentista e admirador de 0scar Wilde, descreve 0 cordão. A prosa de João do Rio é um amálgama vívido da estetização decadentista, na qual as ambivalências elitistas em torno da sexualidade, da mistura de classes e de raças são tingidas por um ávido desejo de ultrapassar a repressão que esta própria ambivalência gera.

0 "outro" exotizado oferece a possibilidades perigosas e fascinantes de contágio, repulsa, descarga sensorial e catártica:

Era em plena Rua do Ouvidor. Não se podia andar. A multidão apertava-se, sufocada. Havia sujeitos congestos, forçando a passagem com os cotovelos, mulheres afogueadas, crianças a gritar, tipos que berravam pilhérias. A pletora da alegria punha desvarios em todas as faces. [...] Na turba compacta 0 alarma correu. 0 cordão vinha assustador. À frente um grupo desenfreado de quatro ou cinco caboclos adolescentes com os sapatos desfeitos e grandes arcos pontudos corria abrindo as bocas em berros roucos. Depois um negralhão todo de penas, com a face Iustrosa como piche, a gotejar suor, estendia 0 braço musculoso e nu sustentando o tacape de ferro. Em seguida gargolejava o grupo vestido de vermelho e amarelo com lantejoulas d'ouro 
a chispar no dorso das casacas e grandes cabeleiras de cachos, que se confundiam com a epiderme num empastamento nauseabundo. Ladeando o bolo, homens em tamancos ou de pés nus iam por ali, tropeçando, erguendo archotes, carregando serpentes vivas sem os dentes, lagartos enfeitados, jabutis aterradores com grandes gritos roufenhos (RI0, 2010, p. 244, 246, 248).

Como é usual nas crônicas jornalísticas de João do Rio, a observação da vida de rua é narrada na primeira pessoa e 0 observador, enquanto flâneur burguês é tanto repelido quanto atraído pelas manifestações do frenético carnaval popular. Entretanto, para explicar pedagogicamente 0 impacto do cordão, João do Rio faz uso do diálogo "socrático" e o narrador da crônica escuta a prédica do seu amigo, que exalta o cordão face às coreografias desvitalizadas dos préstitos e dos bailes mascarados dos salões. Arrebatado pelo embalo da multidão, nosso narrador finalmente concorda e exclama:

Oh! Sim! Ele tinha razão! 0 cordão é o carnaval, é 0 ultimo elo das religiões pagãs, é bem 0 conservador do sagrado dia do deboche ritual; 0 cordão é a nossa alma ardente, luxuriosa, triste, meio escrava e revoltosa, babando lascívia pelas mulheres e querendo maravilhar, fanfarrona, meiga, bárbara, lamentável (RI0, 2010, p. 264).

Para as classes altas que tinham depositado tantas expectativas no embelezamento da cidade mediante as reformas de Passos, os cordões africanizados, o ritmo musical e os animais totêmicos não somente evocavam a ameaça do desregramento caótico como também projetavam espectros fantásticos e atávicos na fachada cosmopolita da cidade. A incompatibilidade entre as normas burguesas com suas noções de modernidade e progresso e a aparição "arquetípica" de deidades, forças e emoções não só produziu uma atmosfera de reencantamento estranhado para o observador burguês como também revelou o fascínio com a multidão. A despeito do seu uso da caricatura e da sátira classista, os escritos de João do Rio transmitem um poderoso reconhecimento das experiências heterogêneas da cidade. 0 cordão fascina, repele e ameaça não apenas porque não condiz com as normas de modernização burguesas, mas também porque traz à tona formas de êxtase coletivo, contágio cultural e celebração no meandro da própria metrópole modernizada.

Desde 0 século XIX, as festividades carnavalescas não somente eram assunto dos jornais como também dependiam destes para a promoção dos desfiles e festejos (GALVÃO, 2009, p. 28-29). Do início do século XX até 1940, os jornalistas associados às festividades formavam 0 nicho específico dos "cronistas de Momo" (COUTINHO, 2006). De 1928 até a década de 1970, 0 Cruzeiro teve um papel crucial em estabelecer as imagens do carnaval, centrados no desfile grandioso das escolas de samba, nos bailes de máscaras ou na festança de foliões anônimos. 0 advento da televisão nos anos 1960 possibilitou que 0 carnaval ganhasse uma dimensão global e a transmissão televisiva alterou a própria estrutura da festividade. Durante a ditadura militar, 0 
carnaval de rua no Rio de Janeiro foi grandemente reduzido. As décadas de 1970 até meados de 1980 foram um período de atividades carnavalescas controladas. A cobertura televisiva e as revistas ilustradas, tais como Fatos \& Fotos e Manchete, vendiam milhares de exemplares com as imagens do desfile glorificado, os clichês de mulatas rebolantes e os retratos de foliões semidespidos e empapados de suor em posições indecorosas nos bailes de carnaval. Mas a presença da multidão carnavalesca nas ruas era tênue. Com a exceção do bloco Banda de Ipanema, criado nos anos 1960 por um grupo irreverente de intelectuais e artistas, e do Cordão do Bola Preta, que, fundado em 1918, mantinha sua verve, as ruas da cidade não eram ocupadas por uma profusão de novos blocos ou foliões.

A volta da multidão carnavalesca nas ruas, agora em quantidades inusitadas e explosivas, acarretou a emergência de centenas de novos blocos que manifestam de formas altamente díspares diversas modalidades de celebrar o carnaval. Blocos de percussão e disfarces, tal como o Cordão do Boi Tatá, existem conjuntamente com blocos efêmeros encampados por patrocinadores ou blocos de celebridades voltados para a transmissão midiática.

\section{Conclusão}

Em termos culturais, 0 apelo popular e midiático do carnaval foi consagrado. A cultura carnavalesca das classes populares se transformou e foi legitimada. Cada vez mais, o carnaval é uma fonte de renda e lucro que beneficia, sobretudo, empresários e mediadores especializados. Mas tal como foi dito antes, 0 carnaval não é somente mídia e comércio. 0 tempo do carnaval é o tempo profano no sentido elaborado por Agamben ( 2007) , pois aquilo que fora abrigado nos domínios dos deuses retorna ao uso do comum e se imiscui na carne do mundo. A profanação carnavalesca, seus impulsos bombásticos, excessivos, alegóricos, destrutivos e criativos lançam 0 sagrado ao solo impuro do mundano.

No sufocado aperto da compactada multidão carnavalesca é quase impossível tirar uma fotografia, é quase impossível ensaiar o gesto prototípico contemporâneo, o gesto de se ver vivendo por meio das imagens. Apesar disso, as imagens dos foliões afogueados circulam nos meios midiáticos e nas redes sociais. Mesmo no âmago da multidão, os foliões têm a consciência imagética de sua autorrepresentação midiática. 0 carnaval não é uma ruptura, não é revolucionário e não pressupõe a inauguração de novos mundos. 0 carnaval pode ser também a experiência do corpo fantasiado que sonha com a perda de si mesmo no abraço de uma coletividade efêmera.

\section{Referências}

AGAMBEN, G. Profanations. New York: Zone Books, 2007.

BILAC, O. Obra reunida. Rio de Janeiro: Nova Aguilar, 1997.

BUCK-MORSS, S. Dreamworld and Catastrophe. Cambridge: MIT Press, 2000. 
CANETTI, E. Crowds and Power. New York: Continuum, 1973.

CAREY, John. The Intellectuals and the Masses:

Pride and Prejudice Among the Literary Intelligentisia, 1880-1939. London: Faber and Faber, 1992.

CARVALHO, J. M. 0s bestializados. São Paulo: Companhia das Letras, 1987.

CAVALCANTI, M. L. V. C. 0 rito e o tempo: ensaios sobre o carnaval. Rio de Janeiro: Civilização Brasileira, 1999.

CAVALCANTI, M. L. V. C.;GONÇALVES, R. Carnaval em múltiplos planos. Rio de Janeiro: Aeroplano, 2008

COUTINHO, Eduardo. 0s cronistas de Momo: imprensa e carnaval na Primeira República. Rio de Janeiro: Editora UFRJ, 2006

CUNHA, M. C. P. Ecos da folia: uma história social do carnaval carioca entre 1880 e 1920. São Paulo: Companhia das Letras, 2001.

DAMATTA, R. Carnavais, malandros e heróis: para uma sociologia do dilema brasileiro, Rio de Janeiro: Rocco, 1997.

HARDT, M.;NEGRI, A. Multitude: war and democracy in the age of Empire. New York: Penguin, 2004.

FERREIRA, F. O livro de ouro do carnaval brasileiro. Rio de Janeiro: Ediouro, 2004. FREYRE, G. Casa Grande e senzala. São Paulo: Global Editora, 2003. Sobrados e mucambos. São Paulo:

Global Editora, 2003.

GALVÃO, W. Ao som do samba: uma leitura do carnaval carioca, São Paulo: Editorial Fundação Perseu Abramo, 2009.
KARASCH, M. C. Slave life in Rio de Janeiro: 1808-1850. Princeton: Princeton University Press, 1987.

JONSSON,S. The Invention of the Masses: The Crowd in French Culture from the Revolution to the Commune. In: SCHNAPPS, J.: TIEWS, M. (Ed). Crowds. Stanford University Press: Stanford, 2006

ORTEGA y GASSET, J. The Revolt of the Masses. New York: W.W. Norton \& Company, 1994.

MORAES, E. História do carnaval carioca. Rio de Janeiro: Civilização Brasileira, 1958.

QUEIROZ, M. I. P.Carnaval brasileiro: o vivido e o mito. São Paulo: Brasiliense, 1992.

RIO, J. A alma encantadora das ruas. Rio de Janeiro: Cidade Viva, 2010.

SCHNAPPS, J.;TIEWS M. Crowds. Palo Alto:

Stanford University Press, 2006.

SENNETT, R. The Fall of Public Man. Cambridge: Cambridge University Press, 1977.

SOIHET, R. A subversão pelo riso. Rio de Janeiro: Fundação Getúlio Vargas, 1998. 


\begin{tabular}{|c|c|}
\hline $\begin{array}{l}\text { Images of the crowd: carnival } \\
\text { and media }\end{array}$ & $\begin{array}{l}\text { Imágenes de la muchedumbre: } \\
\text { carnaval y media }\end{array}$ \\
\hline $\begin{array}{l}\text { Abstract } \\
\text { Through selective readings of literary chronicles, } \\
\text { artistic and media representations, this essay } \\
\text { explores how a particular kind of crowd - the } \\
\text { carnival crowd - has been interpreted and } \\
\text { represented in key periods of Rio de Janeiro's } \\
\text { history. More than any other public celebration, } \\
\text { carnival was and still is the festive ritual that } \\
\text { mirrors most clearly the cultural negotiations of the } \\
\text { city. I argue that different media not only express } \\
\text { the social contradictions and the distinct cultural } \\
\text { negotiations of this profane celebration but they } \\
\text { also shape the experiences of the crowd. } \\
\text { Keywords } \\
\text { Carnival. Crowds. Media. City. }\end{array}$ & $\begin{array}{l}\text { Resumen } \\
\text { Por medio de la lectura selectiva de representaciones } \\
\text { artísticas y mediáticas, este ensayo explora como un } \\
\text { tipo especifico de muchedumbre - la muchedumbre } \\
\text { del carnaval - fue interpretada en diferentes períodos } \\
\text { de la historia de Rio de Janeiro. Más que cualquier } \\
\text { otra celebración pública, el carnaval fue y todavía es } \\
\text { el ritual festivo que mejor espeja las negociaciones } \\
\text { culturales de la ciudad. Argumento que los media } \\
\text { diversos no solamente expresan las contradicciones } \\
\text { sociales y las diferentes negociaciones culturales de } \\
\text { esa celebración profana como también moldan las } \\
\text { propias manifestaciones de la muchedumbre. } \\
\text { Palabras-Clave } \\
\text { Carnaval. Muchedumbre. Media. Ciudad. }\end{array}$ \\
\hline
\end{tabular}




\section{Expediente}

A revista E-Compós é a publicação científica em formato eletrônico da Associação Nacional dos Programas de Pós-Graduação em Comunicação (Compós). Lançada em 2004, tem como principal finalidade difundir a produção acadêmica de pesquisadores da área de Comunicação, inseridos em instituições do Brasil e do exterior.

\section{E-COMPÓS I www.e-compos.org.br I E-ISSN 1808-2599}

Revista da Associação Nacional dos Programas

de Pós-Graduação em Comunicacão.

Brasília, v.16, n.3, set./dez. 2013

A identificação das edições, a partir de 2008

passa a ser volume anual com três números.

\section{CONSELHO EDITORIAL}

Afonso Albuquerque, Universidade Federal Fluminense, Brasil Alberto Carlos Augusto Klein, Universidade Estadual de Londrina, Brasil Alex Fernando Teixeira Primo, Universidade Federal do Rio Grande do Sul, Brasil Ana Carolina Damboriarena Escosteguy, Pontifícia Universidade Católica do Rio Grande do Sul, Brasi

Ana Gruszynski, Universidade Federal do Rio Grande do Sul, Brasil Ana Silvia Lopes Davi Médola, Universidade Estadual Paulista, Brasil André Luiz Martins Lemos, Universidade Federal da Bahia, Brasil Ângela Freire Prysthon, Universidade Federal de Pernambuco, Brasil Antônio Fausto Neto, Universidade do Vale do Rio dos Sinos, Brasil Antonio Carlos Hohlfeldt, Pontifícia Universidade Católica do Rio Grande do Sul, Brasil Antonio Roberto Chiachiri Filho, Faculdade Cásper Líbero, Brasil Arlindo Ribeiro Machado, Universidade de São Paulo, Brasil Arthur Autran Franco de Sá Neto, Universidade Federal de São Carlos, Brasil Benjamim Picado, Universidade Federal Fluminense, Brasil César Geraldo Guimarães, Universidade Federal de Minas Gerais, Brasil Cristiane Freitas Gutfreind, Pontifícia Universidade Católica do Rio Grande do Sul, Brasil Denilson Lopes, Universidade Federal do Rio de Janeiro, Brasi Denize Correa Araujo, Universidade Tuiuti do Paraná, Brasi Edilson Cazeloto, Universidade Paulista , Brasil

Eduardo Peñuela Cañizal, Universidade Paulista, Brasil

Eduardo Vicente, Universidade de São Paulo, Brasi

Eneus Trindade, Universidade de São Paulo, Brasi

Erick Felinto de Oliveira, Universidade do Estado do Rio de Janeiro, Brasi

Florence Dravet, Universidade Católica de Brasília, Brasi

Francisco Eduardo Menezes Martins, Universidade Tuiuti do Paraná, Brasil

Gelson Santana, Universidade Anhembi/Morumbi, Brasi

Gilson Vieira Monteiro, Universidade Federal do Amazonas, Brasil

Gislene da Silva, Universidade Federal de Santa Catarina, Brasil

Guillermo Orozco Gómez, Universidad de Guadalajara

Gustavo Daudt Fischer, Universidade do Vale do Rio dos Sinos, Brasil Hector 0spina, Universidad de Manizales, Colômbia

Herom Vargas, Universidade Municipal de São Caetano do Sul, Brasi leda Tucherman, Universidade Federal do Rio de Janeiro, Brasil

Inês Vitorino, Universidade Federal do Ceará, Brasil

Janice Caiafa, Universidade Federal do Rio de Janeiro, Brasil

Jay David Bolter, Georgia Institute of Technology

Jeder Silveira Janotti Junior, Universidade Federal de Pernambuco, Brasil João Freire Filho, Universidade Federal do Rio de Janeiro, Brasil
John DH Downing, University of Texas at Austin, Estados Unidos

José Afonso da Silva Junior, Universidade Federal de Pernambuco, Brasi José Carlos Rodrigues, Pontifícia Universidade Católica do Rio de Janeiro, Brasil José Luiz Aidar Prado, Pontifícia Universidade Católica de São Paulo, Brasil José Luiz Warren Jardim Gomes Braga, Universidade do Vale do Rio dos Sinos, Brasil Juremir Machado da Silva, Pontifícia Universidade Católica do Rio Grande do Sul, Brasil Laan Mendes Barros, Universidade Metodista de São Paulo, Brasi Lance Strate, Fordham University, USA, Estados Unidos Lorraine Leu, University of Bristol, Grã-Bretanha Lucia Leão, Pontifícia Universidade Católica de São Paulo, Brasil Luciana Panke, Universidade Federal do Paraná, Brasil Luiz Claudio Martino, Universidade de Brasília, Brasi Malena Segura Contrera, Universidade Paulista, Brasil

Márcio de Vasconcellos Serelle, Pontifícia Universidade Católica de Minas Gerais, Brasil Maria Aparecida Baccega, Universidade de São Paulo e Escola Superior de Propaganda e Marketing, Brasi

Maria das Graças Pinto Coelho, Universidade Federal do Rio Grande do Norte, Brasil Maria Immacolata Vassallo de Lopes, Universidade de São Paulo, Brasil Maria Luiza Martins de Mendonça, Universidade Federal de Goiás, Brasil Mauro de Souza Ventura, Universidade Estadual Paulista, Brasil

Mauro Pereira Porto, Tulane University, Estados Unidos

Nilda Aparecida Jacks, Universidade Federal do Rio Grande do Sul, Brasi Paulo Roberto Gibaldi Vaz, Universidade Federal do Rio de Janeiro, Brasi Potiguara Mendes Silveira Jr, Universidade Federal de Juiz de Fora, Brasi Renato Cordeiro Gomes, Pontifícia Universidade Católica do Rio de Janeiro, Brasil Robert K Logan, University of Toronto, Canadá Ronaldo George Helal, Universidade do Estado do Rio de Janeiro, Brasil Rosana de Lima Soares, Universidade de São Paulo, Brasi Rose Melo Rocha, Escola Superior de Propaganda e Marketing, Brasil Rossana Reguillo, Instituto de Estudos Superiores do Ocidente, Mexico Rousiley Celi Moreira Maia, Universidade Federal de Minas Gerais, Brasi Sebastião Carlos de Morais Squirra, Universidade Metodista de São Paulo, Brasil Sebastião Guilherme Albano da Costa, Universidade Federal do Rio Grande do Norte, Brasil

Simone Maria Andrade Pereira de Sá, Universidade Federal Fluminense, Brasi Tiago Quiroga Fausto Neto, Universidade de Brasília, Brasil Suzete Venturelli, Universidade de Brasília, Brasil Valerio Fuenzalida Fernández, Puc-Chile, Chile

Veneza Mayora Ronsini, Universidade Federal de Santa Maria, Brasi Vera Regina Veiga França, Universidade Federal de Minas Gerais, Brasil

COMISSÃO EDITORIAL

Adriana Braga I Pontifícia Universidade Católica do Rio de Janeiro, Brasil

CONSULTORES AD HOC

Adriana Amaral, Universidade do Vale do Rio dos Sinos, Brasil

Alexandre Rocha da Silva, Universidade Federal do Rio Grande do Sul, Brasi

Arthur Ituassu, Pontifícia Universidade Católica do Rio de Janeiro, Brasil

Bruno Souza Leal, Universidade Federal de Minas Gerais, Brasil

Elizabeth Bastos Duarte, Universidade Federal de Santa Maria, Brasil

Francisco Paulo Jamil Marques, Universidade Federal do Ceará, Brasi

Maurício Lissovsky, Universidade Federal do Rio de Janeiro, Brasi

Suzana Kilpp, Universidade do Vale do Rio dos Sinos, Brasil

Vander Casaqui, Escola Superior de Propaganda e Marketing, Brasil

EDIÇÃO DE TEXTO E RESUMOS I Susane Barros

SECRETÁRIA EXECUTIVA I Juliana Depiné

EDITORAÇÃO ELETRÔNICA I Roka Estúdio

TRADUÇÃ̃o I Sieni Campos
COMPÓS I www.compos.org.br

Associação Nacional dos Programas de Pós-Graduação em Comunicação

Presidente

Eduardo Morettin

Universidade de São Paulo, Brasil

eduardomorettin@usp.br

Vice-presidente

Inês Vitorino

ines@ufc.br

Secretária-Geral

Gislene da Silva

Universidade Federal de Santa Catarina, Brasi

gislenedasilva@gmail.com
Universidade Federal do Ceará, Brasil 